Boise State University

ScholarWorks

Geosciences Faculty Publications and

Presentations

Department of Geosciences

8-16-2015

\title{
Lahar Infrasound Associated with Volcán Villarrica's 3 March 2015 Eruption
}

Jeffrey B. Johnson

Boise State University

Jose L. Palma

University of Concepción

This document was originally published by Wiley on behalf of the American Geophysical Union in Geophysical

Research Letters. Copyright restrictions may apply. doi: 10.1002/2015GL065024 


\section{Geophysical Research Letters}

\section{RESEARCH LETTER \\ 10.1002/2015GL065024 \\ Key Points: \\ - Lahar is monitored for the first time using infrasound array \\ - Advancement of lahar was $38 \mathrm{~m} / \mathrm{s}$ over $10 \mathrm{~km}$ section; detected flow lasted more than $2 \mathrm{~h}$ \\ - Use of infrasound surveillance has potential for future lahar study and hazard mitigation}

Supporting Information:

- Readme

- Movie S1

Correspondence to:

J. B. Johnson,

jeffreybjohnson@boisestate.edu

Citation:

Johnson, J. B., and J. L. Palma (2015), Lahar infrasound associated with Volcán Villarrica's 3 March 2015 eruption, Geophys. Res. Lett., 42, 6324-6331, doi:10.1002/2015GL065024.

Received 20 JUN 2015 Accepted 27 JUL 2015

Accepted article online 30 JUL 2015 Published online 14 AUG 2015
(C2015. American Geophysical Union All Rights Reserved.

\section{Lahar infrasound associated with Volcán Villarrica's 3 March 2015 eruption}

\author{
Jeffrey B. Johnson ${ }^{1}$ and Jose L. Palma ${ }^{2}$ \\ ${ }^{1}$ Department of Geosciences, Boise State University, Boise, Idaho, USA, ${ }^{2}$ Department of Earth Sciences, University of \\ Concepción, Concepción, Chile
}

\begin{abstract}
The paroxysmal 2015 eruption of Volcán Villarrica (Chile) produced a $2.5 \mathrm{~h}$ long lahar, which descended more than $20 \mathrm{~km}$ within the Rio Correntoso/Turbio drainage and destroyed two small bridges. A three-element infrasound array $10 \mathrm{~km}$ from the summit, and $4 \mathrm{~km}$ from the lahar's closest approach, was used to study the flow's progression. Array processing using cross-correlation lag times and semblance places constraints on the lahar's dynamics, including detection of an initial flow pulse that traveled from 2 to $12 \mathrm{~km}$ at an average speed of $38 \mathrm{~m} / \mathrm{s}$. Subsequently, the lahar signal evolved to a relatively stationary infrasonic tremor located 10 to $12 \mathrm{~km}$ from the vent and adjacent to a topographic notch, through which sound may have preferentially diffracted toward the recording site. This study demonstrates the powerful capabilities of infrasound arrays for lahar study and suggests their potential application for future hazard monitoring.
\end{abstract}

\section{Introduction}

Lahars are one of the principal hazards at volcanoes. The most deadly historic lahar occurred in 1985 at Nevado del Ruiz (Colombia) when eruption-induced glacial melting produced flows that traveled further than $100 \mathrm{~km}$ and killed more than 25,000 people [Lowe et al., 1986]. Lahars, such as those at Nevado del Ruiz, may be generated coincidentally with volcanic eruptions or can initiate as secondary flows following rain events on ash-covered slopes, failure of crater lake impoundments, or spontaneous erosion or collapse of volcanic slopes [Vallance, 2000]. Efforts to mitigate lahar hazards focus on the timely upstream identification of flows and the relay of warnings to downstream authorities and the public. Such monitoring currently entails a wide spectrum of techniques, including radio-equipped human observers (e.g., Tungurahua, Ecuador), webcams (e.g., at Sakurajima, Japan), and networks of telemetered geophones, stream gauges, or "acoustic flow monitors" (e.g., at Merapi, Indonesia [Lavigne et al., 2000]). Geophone lahar detection, termed "acoustic flow monitoring," relies upon identification of high-frequency, high-amplitude tremor using duration threshold criteria [Hadley and LaHusen, 1995]. Our study presents a lahar case study from Volcan Villarrica and introduces "infrasound flow monitoring" as a potential complementary monitoring technique.

Low-frequency sound monitoring, typically in the infrasound $(<20 \mathrm{~Hz})$ band, is utilized in volcanology as both an eruption surveillance tool and as an instrument to improve understanding of eruption dynamics and flow phenomena [e.g., Johnson and Ripepe, 2011; Fee and Matoza, 2013]. Dynamics of volcanic pyroclastic flows, for instance, have been investigated at Soufrière Hills, Montserrat [Ripepe et al., 2009], and Unzen, Japan [Yamasato, 1997], using arrays and networks of infrasound sensors, respectively. Nonvolcanic gravity-driven flows, such as snow avalanches, have also been studied using infrasound array processing techniques [e.g., Havens et al., 2014]. Gravity-driven flows, such as pyroclastic currents, snow avalanches, lahars, and other types of debris flows [Kogelnig et al., 2014], produce inherently complex signal because the radiation source is moving and is often noncompact with respect to radiated acoustic energy. Arrays of acoustic sensors provide important beam-forming constraints that permit the tracking of moving, and/or distributed, low signal-to-noise sources.

\section{Volcán Villarrica Background}

Villarrica is Chile's most regular active volcano and typically hosts an open-vent lava lake with a surface located some few hundred meters beneath the summit crater rim [Palma et al., 2008]. Infrequent paroxysmal eruptive periods, punctuated by volcanic explosivity index (VEI) 2 events, occur with repeat intervals of every few decades [Van Daele et al., 2014]. Periods of heightened activity typically last months to years, such as the 
a)
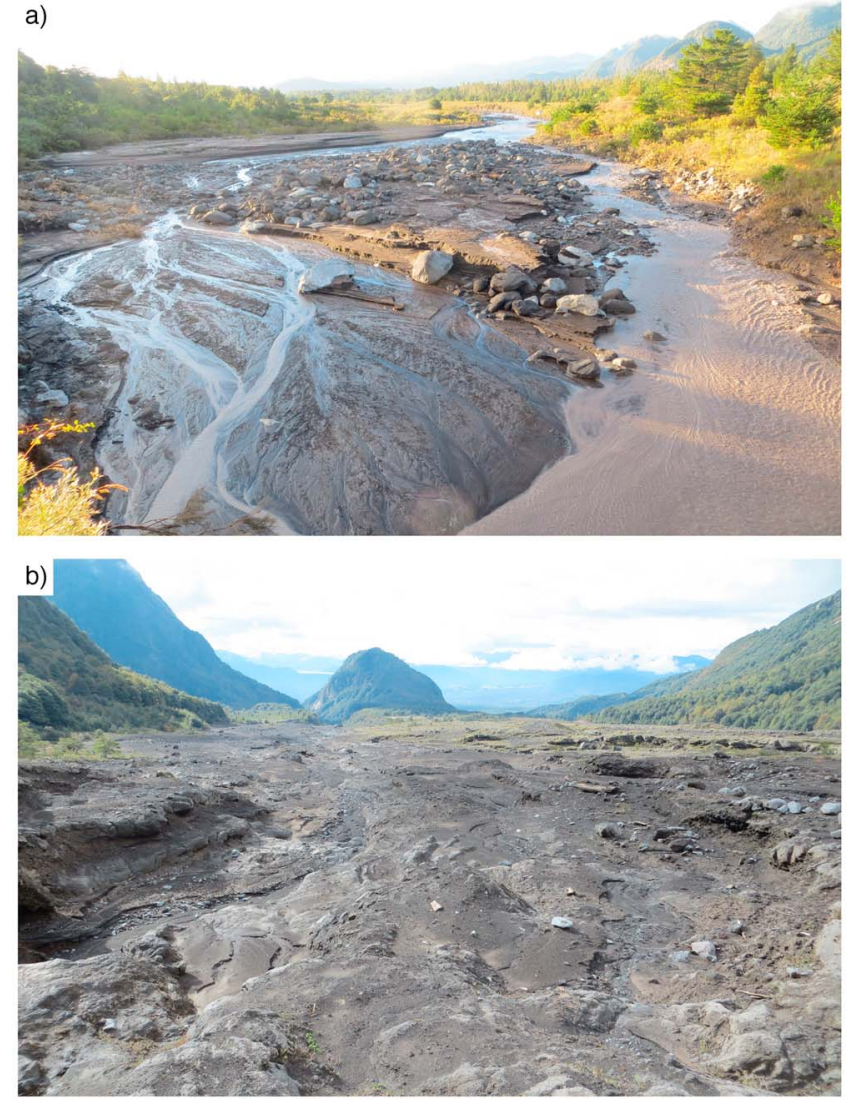

Figure 1. (a) A 6 March photo from Rio Turbio Bridge (17.2 km LFD from summit) looking upstream and showing fresh lahar deposits. (b) A 5 April photo from Correntoso at $8 \mathrm{~km}$ LFD looking downstream. The lahar flowed through the deep canyon to the left of the prominent hill. most recent elevated activity in 1971 and 1984-85, when lahars cut bridges on both southern and northern sides of the volcano [Siebert and Simkin, 2002]. Lahar records from lake core sediment indicate similar activity for at least 22 eruptions occurring during the last 600 years [Van Daele et al., 2014].

Paroxysmal eruptions and eruptioninduced laharic activity had been absent at Villarrica for 30 years, from 1985 until the 2015 activity featured in this study. Starting in early February of 2015 , high levels of seismicity, increasing vent infrasound, and observations of ash venting and ballistics ejection prompted an elevation in volcanic alert (reports at www.onemi.cl). On 2 March, the Chilean monitoring agency Servicio Nacional de Geología y Minería issued a timely red alert and the Chilean security ministry Oficina Nacional de Emergencia del Ministerio del Interior extended the exclusion zone to $9 \mathrm{~km}$.

On the morning of 3 March vigorous strombolian activity preceded a paroxysmal $1500 \mathrm{~m}$ high lava fountain that grew starting at 3:00 A.M. (local time) and terminated about a half an hour later. This brief but violent VEI 2

paroxysm produced heavy tephra fall to the east and incandescent scoria flows predominantly on the north and east flanks, which were well observed from the city of Pucon at $17 \mathrm{~km}$ distance. These flows appeared as rolling blocks and slurries of incandescent material descending atop frozen surfaces and reaching distances of at least $1 \mathrm{~km}$. Explosive lava fountaining, which coincided with vent-sourced infrasound, tapered quickly and terminated by about 3:30 A.M. Ensuing activity consisted of the collapse of unstable blocks on the slopes and laharic activity in drainages to the NNW and a larger lahar, which descended to the NNE.

We refer to this NNE flow path as the Correntoso/Turbio (CT), noting that although the Correntoso appears on many maps, some sources refer to the upper tributary as the Pedgregoso. The CT flow destroyed two small bridges with earthen abutments, located at 13.5 and $14.5 \mathrm{~km}$ longitudinal flow distances (LFD) from the summit and just upstream of the confluence of the Correntoso and Turbio Rivers (at $15.5 \mathrm{~km}$ LFD). The much larger steel-girdered bridge over the Turbio at $17.2 \mathrm{~km}$ LFD was not damaged despite evidence of high-energy flow, including deposition of meter-sized blocks at this distance (see Figure $1 \mathrm{a}$ ).

\section{Study}

Acquisition of the 3 March lahar infrasound signal was serendipitous in that a network of infrasound sensors had recently been deployed around Villarrica in January and February with the intent to understand atmospheric propagation phenomena. These stations complemented a permanent six-element infrasound array (VIX) located $8 \mathrm{~km}$ from the vent, which is used to continuously monitor variations in volcanic unrest. The temporary 5 month deployment consisted of 30 infrasonic microphones deployed as 10 three-element infrasound arrays at a range of azimuths and distances (from $22 \mathrm{~km}$ to the summit itself, where sensors were destroyed on 3 March). The objectives of both the short-term and permanent installations were to better understand the 


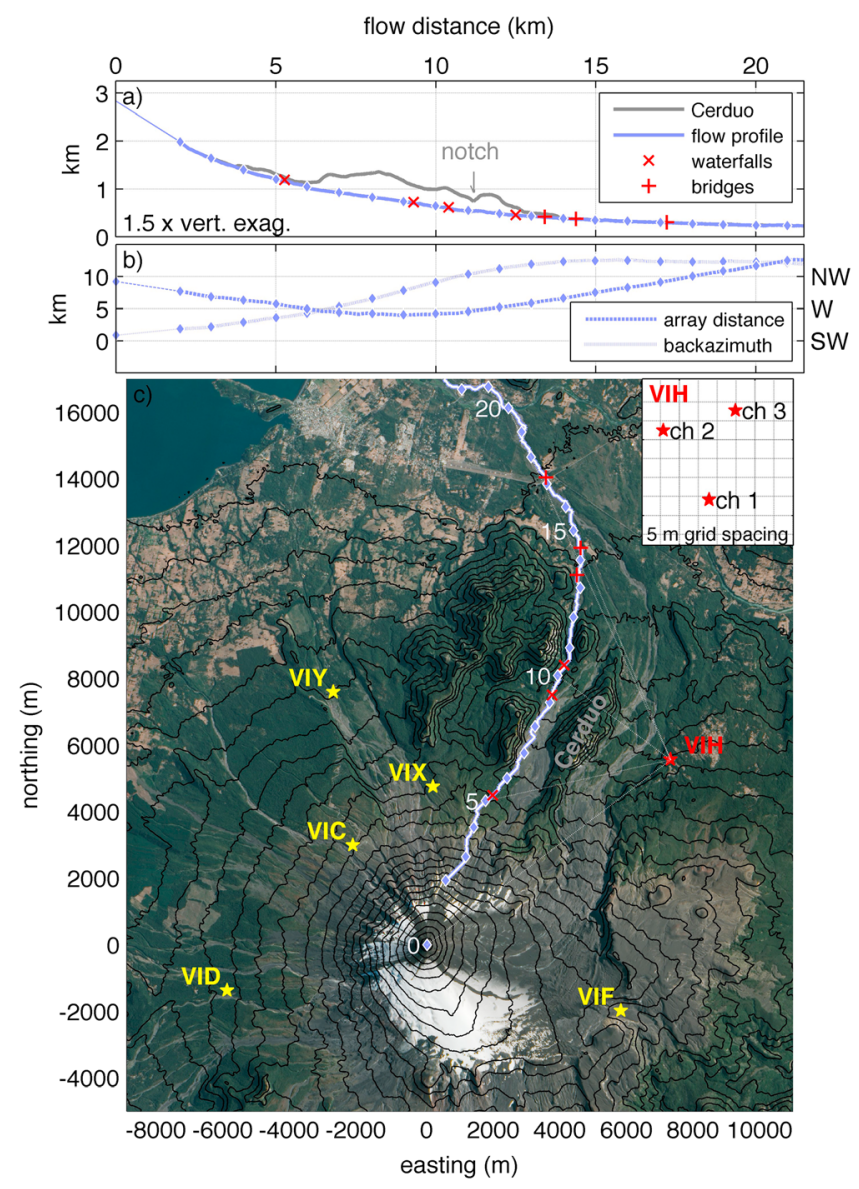

Figure 2. (a) Longitudinal flow profile of the CT. Diamonds indicate $1 \mathrm{~km}$ LFD ticks. Cerduo profile corresponds to the relative height of the intervening topography between Array VIH and the CT drainage. Locations of bridges and significant waterfalls are indicated. (b) Slant distance and back azimuth between flow profile and Array VIH. (c) Advanced Spaceborne Thermal Emission and Reflection Radiometer (ASTER) Global Digital Elevation Map (GDEM) topography-derived $100 \mathrm{~m}$ contours draped on NASA EO-1 ALI image acquired on 9 March. Inset shows relative locations of infrasound sensors. continuous and especially intense infrasound produced by Villarrica's open vent [Ripepe et al., 2009; Goto and Johnson, 2011; Richardson et al., 2014] and to characterize the effects of dynamic atmospheric structure on infrasound propagation [e.g., Johnson et al., 2012]. The location of six infrasound arrays is indicated on the map of Figure 2, and example infrasound records from these stations are provided in Figure 3. Array $\mathrm{VIH}$ recorded the $\mathrm{CT}$ lahar signal with the greatest fidelity and is featured in this work.

Infrasonic microphones at all stations were composed of infraBSU Microelectromechanical systems based differential pressure transducers with an operation similar to that described in Marcillo et al. [2012]. Sensor corner frequency ( $3 \mathrm{~dB}$ down) was at $0.045 \mathrm{~Hz}$ (22 s), and intrinsic RMS noise levels in the $1-10 \mathrm{~Hz}$ band were at $\sim 2 \mathrm{mPa}$. Microphone arrays consisted of a spatial distribution of sensors connected to a central datalogger with signal and power cable. Array aperture of $\mathrm{VIH}$ was $\sim 25 \mathrm{~m}$, and nodal locations were surveyed to an accuracy of $\sim 50 \mathrm{~cm}$ using compass and measuring tape (Figure 2 inset). Data at VIH were acquired continuously at $100 \mathrm{~Hz}$ using DataCube 24 bit, three-channel digitizers with GPS time synchronization.

Infrasound records from the six mapped arrays reveal a combination of common and more local signal source generation (Figure 3). Gross waveform features that are shared across the network, and which possess similar waveform envelope and reduced pressure amplitudes, are relatable to summit or vent activity. Coherent sound that is only evident on individual arrays suggests that a source is preferentially located either closer to or within line of sight of that array. Generally, high-pass-filtered infrasound $(>10 \mathrm{~Hz})$ appears to accentuate signal differences leading us to conclude that high frequencies predominate for potential lahar sources. The most striking example of coherent infrasound that is pronounced on a single array is the more than $2 \mathrm{~h}$ long rapidly rising and slowly decaying tremor beginning 03:25 A.M. on Array VIH. Other arrays, including VIC, VIX, and VIY, also recorded high-frequency moving source signals, but these records were significantly lower in intensity and possessed inferior signal-to-noise quality compared to that of $\mathrm{VIH}$.

\subsection{Lahar Source Tracking}

Lahar signal contains comparatively high-frequency energy relative to the infrasound from Villarrica vent activity, which is manifested by strombolian and lava fountaining, as well as passive $\sim 1 \mathrm{~Hz}$ degassing signal [e.g., Ripepe et al., 2009; Goto and Johnson, 2011; Richardson et al., 2014]. The spectral evolution of the lahar recorded by the $\mathrm{VIH}$ array shows a broadband character that begins with prominent high-frequency energy 


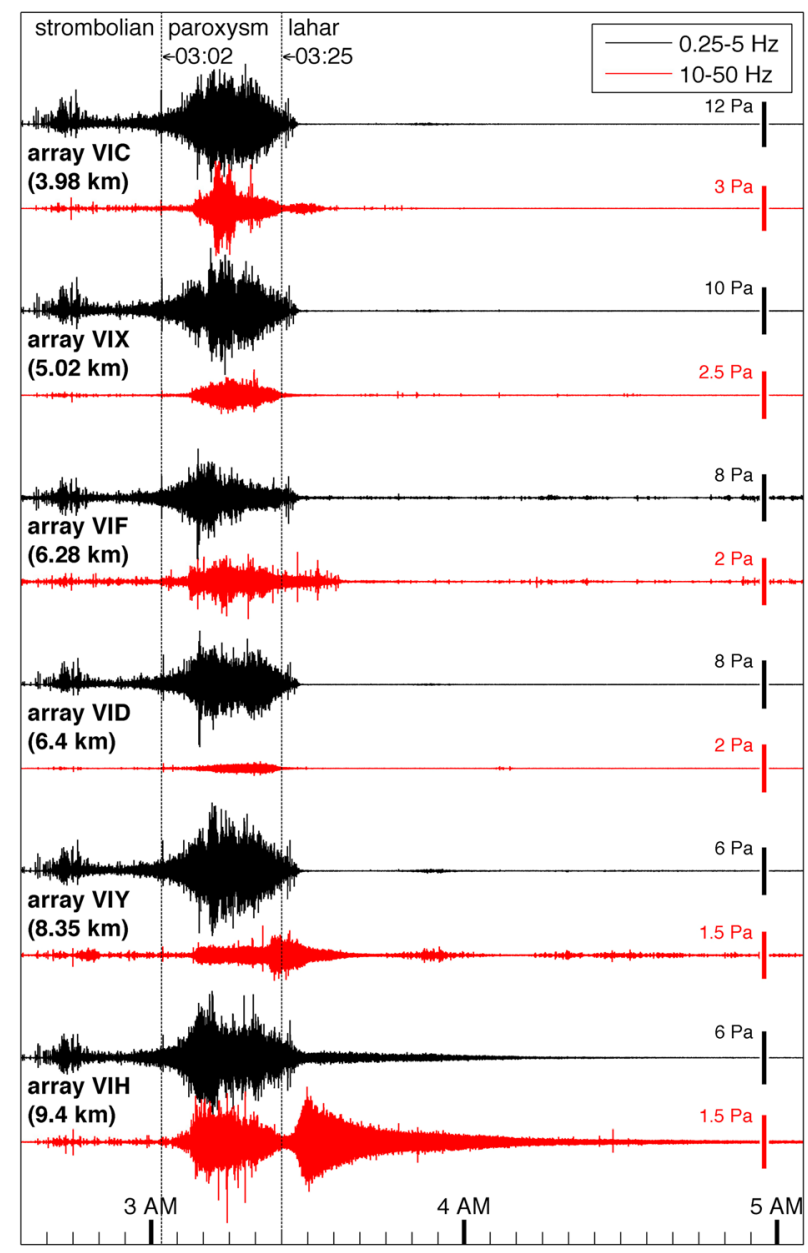

Figure 3. Infrasound records from six arrays filtered in the $0.25-5 \mathrm{~Hz}$ (black) and $10-50 \mathrm{~Hz}$ (red) bands. Records are displayed with their recorded pressures but are scaled to a common reduced pressure using the distances shown in parentheses. Labels of strombolian, paroxysm, and lahar correspond to periods of discrete explosive pulses, culminating lava fountain, and CT lahar periods, respectively.

calculated for each candidate source location ( $x, y$, and $z$ as a function of LFD) and for each overlapping 55 time window centered at time $t$ :

$$
R(x, y, z, t)=\sqrt{\left(\Delta \phi_{2-1}-\Delta \tau_{2-1}\right)^{2}+\left(\Delta \phi_{3-2}-\Delta \tau_{3-2}\right)^{2}+\left(\Delta \phi_{1-3}-\Delta \tau_{1-3}\right)^{2}}
$$

where $\Delta \tau_{i-j}$ is the measured time lag between channels $i$ and $j$ and $\Delta \phi_{i-j}$ is the calculated time lag for sound propagating at $340 \mathrm{~m} / \mathrm{s}$ and is a function of source position.

Low residual values can be mapped over time (see Figures $4 \mathrm{f}$ and $5 \mathrm{~b}$ and Movie S1 in the supporting information) and indicate dynamic acoustic source locations. LFD uncertainty increases for candidate source locations with shared common back azimuths (see Figure $2 \mathrm{~b}$ ). Conversely, best locations are obtained when the flow path is perpendicular to the source-receiver direction, e.g., at LFD of $\sim 9 \mathrm{~km}$, where a residual error of $10 \mathrm{~ms}$ corresponds to LFD location uncertainty of $800 \mathrm{~m}$. At further distances along the CT, beyond $\sim 16 \mathrm{~km}$, potential source locations cannot be resolved using Array VIH.

The locations determined by minimizing equation (1) determines a point location of the most intense sound signal recorded by the array for that time window. Sound source detection is potentially biased by source proximity, such that more distant sources are underrepresented. Moreover, the lahar acoustic source is most 


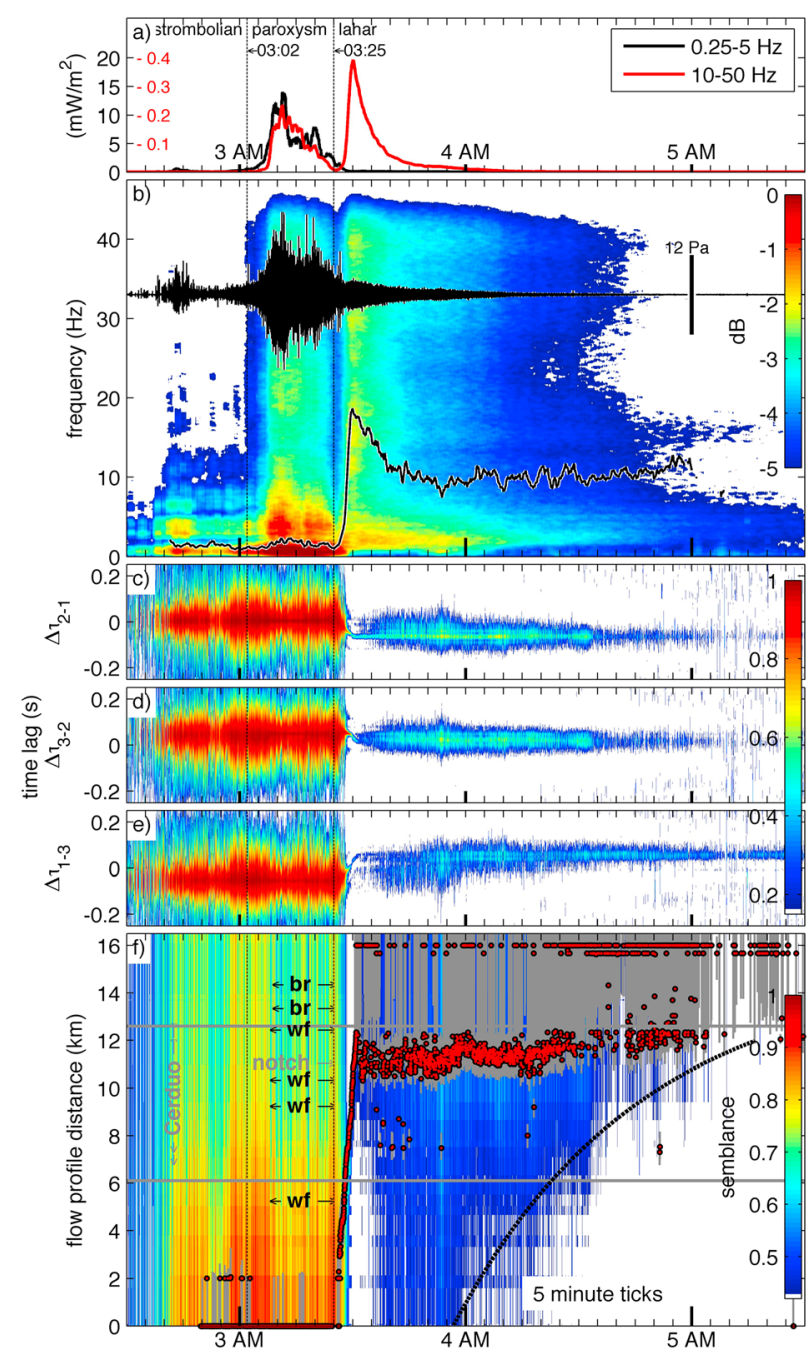

Figure 4. Analysis of $3 \mathrm{~h}$ time series encompassing summit eruptive activity and ensuing lahar. (a) Acoustic intensity recorded at Array $\mathrm{VIH}$ for two primary bands. (b) Broadband acoustic waveform $(0.25-50 \mathrm{~Hz})$ and corresponding spectrogram with centroid frequency shown as black line. (c-e) Correlograms showing intersensor-normalized cross-correlation values as a function of signal time ( $x$ axis) and phase lag ( $y$ axis). Highest correlation color values correspond to principal correlation time lags (in seconds) between the three sensor pairs. (f) Inferred source LFD tracked over time according to residual equation (1) and semblance equation (2) source localization. Residual timing uncertainty of $0.01 \mathrm{~s}$ is indicated with vertical gray lines. Black dashed line corresponds to inferred trailing edge of active flow. Distances of bridges and significant waterfalls in the CT are indicated. All calculations, including cross correlation, spectrogram, and flow locations, are made for $5 \mathrm{~s}$ windows with $4 \mathrm{~s}$ overlap.

likely a noncompact region. We speculate that active lahars flow over a longitudinal extent, which likely radiate sound as a complex superposition of sources, yet only one (prominent) source position is determined using cross correlation.

An alternate and complementary technique to map evolving acoustic source distributions uses semblance, which is a measure of signal to noise of the array beam stack [Neidell and Taner, 1971]. Expected interelement time shifts are calculated for each point along the flow path, and the recorded acoustic signals $\partial p_{i}$ are accordingly shifted, stacked, and normalized.

$$
S(x, y, z, t)=\frac{\left(\partial p_{1}(t)+\partial p_{2}\left(t+\Delta \phi_{2-1}\right)+\partial p_{3}\left(t+\Delta \phi_{3-1}\right)\right)^{2}}{3 \partial p_{1}^{2}(t) \partial p_{2}^{2}\left(t+\Delta \phi_{2-1}\right) \partial p_{3}^{2}\left(t+\Delta \phi_{3-1}\right)}
$$

As with lag time residual analysis, the average semblance value is computed for $5 \mathrm{~s}$ windows overlapping by $4 \mathrm{~s}$ where $x, y$, and $z$ are functions of LFD. 

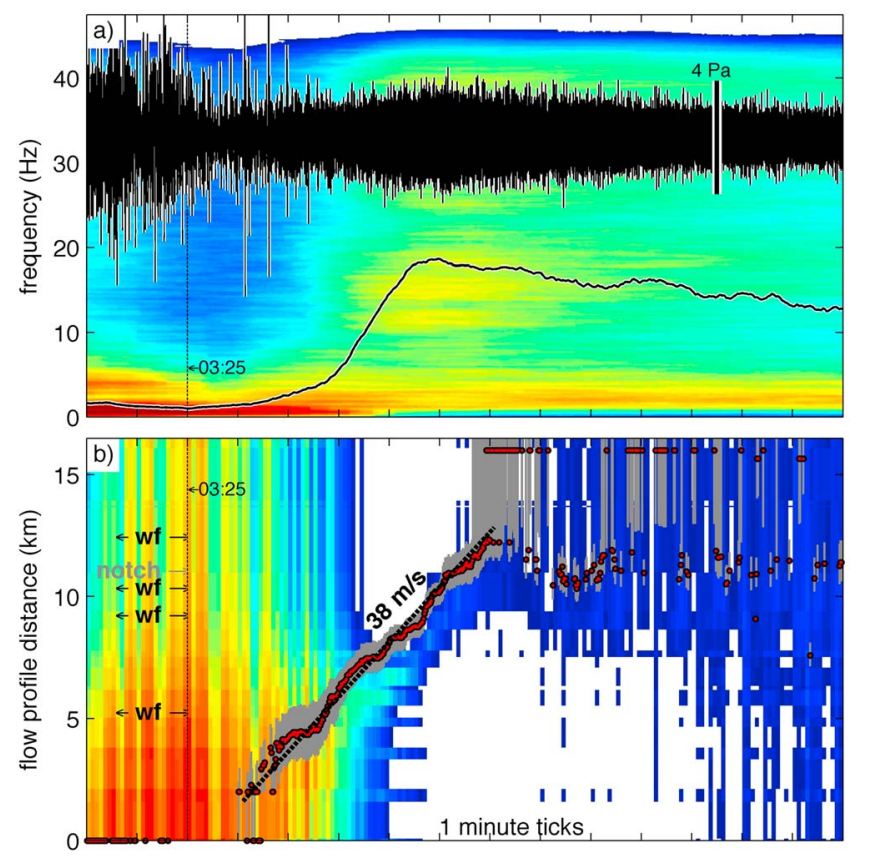

Figure 5. Fifteen minute detail of advancing lahar. (a) Captions and colormap values are the same as for Figure $4 \mathrm{~b}$. (b) Captions and colormap values are the same as for Figure $4 \mathrm{f}$. Linear regression $(38 \pm 1 \mathrm{~m} / \mathrm{s})$ is calculated for indicated $270 \mathrm{~s}$. Animation of the corresponding source movement is provided in supporting information materials.

it represents the high end of previously measured lahar velocities but is within the bounds of lahars flowing close to a volcano and on steep slopes. Though it is higher than the averaged speeds of the 1985 Nevado del Ruiz lahars (5-15 m/s [Lowe et al., 1986]), as well as lahars measured at Ruapehu in 2007 (less than $16 \mathrm{~m} / \mathrm{s}$ [Lube et al., 2012]) and those inferred at Popocatepetl, Mexico (1-14 m/s [Munoz-Salinas et al., 2007]), it is consistent with proximal lahar velocities (30-40 m/s) determined at Mount St. Helens [Pierson, 1985]. We propose that Villarrica lahar tracking during the initial 5 min could correspond to the energetic bow wave and/or head, which contains the bulk of the kinetic flow power [Lube et al., 2012]. After 03:31.0 the mapped lag-time sound source locations cease to advance rapidly and remain relatively fixed within a LFD range of $\sim 10-13 \mathrm{~km}$.

After 03:31 until approximately 05:30 coherent sound remains detectable and appears to originate from a LFD range of $\sim 10$ to $12 \mathrm{~km}$ and also at $>16 \mathrm{~km}$, where precise location is ambiguous due to the distal LFD uncertainty discussed previously. The source distribution at 10-12 km is close to, but not precisely coincident with, two substantial CT waterfalls (with drops of more than $10 \mathrm{~m}$ ) located at 9.2 and $10.3 \mathrm{~km} \mathrm{LFD.} \mathrm{Notably,}$ this source range also coincides with a topographic saddle in the intervening Cerduo cordillera (see Figure 2a). We speculate that substantial lahar sound may be generated at the waterfalls and throughout the canyon between 10 and $12 \mathrm{~km}$ but that it preferentially diffracts around the $11.1 \mathrm{~km}$ LFD saddle. Toward 05:00 the sources appear to shift slightly downstream and cluster between 11.5 and $12.0 \mathrm{~km}$ and near the terminus of the CT canyon, from where sound is able to propagate near line of sight to Array VIH.

Throughout this period, when sources remain between 10 and $12 \mathrm{~km}$, the flow tremor intensity diminishes while the centroid frequency remains fixed at about $10 \mathrm{~Hz}$. This is suggestive of a stable source dimension but potentially diminished flow discharge. Notably, the last detections at $\sim 11 \mathrm{~km}$ are at about 04:30 and the last detections at $\sim 12 \mathrm{~km}$ are at $\sim 05: 00$, whereas detections further downstream at $16 \mathrm{~km}$ continue until at least 05:30. This, together with semblance-inferred source localization, suggests the gradual downstream translation of the sound-generating lahar.

Semblance-inferred sources yield crude spatial resolution but may give a sense of the (broad) distribution of potential sources along the CT flow channel. Following the flow initiation (from 03:26 to 03:31), we observe distributed regions of high semblance values suggestive of sound that is produced along an extended LFD. 
Starting at 03:40 semblance remains highly along the entire active flow length (out to more than $16 \mathrm{~km}$ ), but by around $\sim 04: 00$ semblance diminishes in the upper CT as the bulk of the active lahar migrates downstream. By 04:30 high semblance values indicate sources primarily at $10 \mathrm{~km}$ or further downstream.

\section{Discussion: Potential for Infrasound Flow Monitoring}

Villarrica's 3 March lahar in the CT drainage has a clear acoustic fingerprint that could be used as part of an early warning system. Both the spectral character of the lahar and, more significantly, the changing interarray-correlated time lags distinguish its genesis from that of summit eruptive activity and point to a moving source. The envelope of the lahar signal, and its evolving frequency content, is reminiscent of nonvolcanic debris flows studied in the European Alps using a single infrasonic microphone and geophone [Kogelnig et al., 2014]; that study demonstrated a clear correlation between distinct flow surges and infrasonic tremor intensity. In the case of the CT an infrasound warning of a propagating lahar might be generated some 30-60 min prior to, or 12-15 km above, the flow's impact with the critical international highway bridge over the Turbio River. The 3 March event did not damage this bridge, but larger events would put this bridge, as well as residential developments further downstream, in jeopardy.

The 3 March lahar signal was well detected by a single three-element acoustic array for a range of distances ( 2 to $16 \mathrm{~km}$ LFD) and despite significant intervening topography (from 6.5 to $13 \mathrm{~km}$ LFD). These results attest to the remote sensing potential of this technology; however, we conclude that proper localization of an acoustic surveillance array, or arrays, is critical. A limitation of the Array VIH site was its inability to resolve source locations beyond $\sim 16 \mathrm{~km}$. Future source tracking ambiguity could be ameliorated by more selective location of the array (or arrays). Notably, other nearby Villarrica infrasound arrays, which were located further from the distal portions of the CT and behind significant topography, failed to clearly identify the CT event. These observations argue for implementation of infrasound array monitoring in multiple drainages where hazards might be expected.

Further work relating empirical observations of lahar flow to acoustic radiation is necessary and might also lead to real-time assessments of flow size and hazard. Future study should also include acoustic monitoring that extends above the traditional band of volcano infrasound used for eruption detection [Johnson and Ripepe, 2011]. This will require higher sampling rates and experimentation with potentially smaller array apertures to optimize signal coherence, and avoid aliasing, for higher frequency recordings.

\section{Conclusions}

The 3 March lahar of the CT drainage was tracked acoustically from near source to more than $13 \mathrm{~km}$ flow distance. Important constraints on initial flow speed $(38 \pm 1 \mathrm{~m} / \mathrm{s})$ were afforded by a single $25 \mathrm{~m}$ aperture, three-element array. The moderate-sized CT lahar remained detectable for more than $2 \mathrm{~h}$ despite the fact that the lahar flow path was 4-10 km from Array VIH and much of its length, from 6.5 to $13 \mathrm{~km}$ LFD, was not directly within line of sight. Lahar intensity and frequency content is greatest during the initial lahar advance. The abundance of coherent high-frequency energy argues for the usage of both infrasound and low-frequency audio band monitoring.

Acknowledgments

We thank Jesse Allen and the NASA EO-1 team and the U.S. Geological Survey for ALI imagery and acknowledge usage of the ASTER GDEM $30 \mathrm{~m}$ data product from gdem.ersdac.jspacesystems.or.jp/. This work was made possible with support from the National Science Foundation EAR grant 1151662, the Fulbright Scholar's Program, CONICYT Inserción grant 791100021, and FONDECYT Iniciación grant 11121335. Data used in this study are available upon request.

The Editor thanks Richard LaHusen and an anonymous reviewer for their assistance in evaluating this paper.

\section{References}

Fee, D., and R. S. Matoza (2013), An overview of volcano infrasound: From Hawaiian to Plinian, local to global, J. Volcanol. Geotherm. Res., 249, 123-139, doi:10.1016/j.jvolgeores.2012.09.002.

Goto, A., and J. B. Johnson (2011), Monotonic infrasound and Helmholtz resonance at Volcan Villarrica (Chile), Geophys. Res. Lett., 38, L06301, doi:10.1029/2011GL046858.

Hadley, K. C., and R. G. LaHusen (1995), Technical manual for Acoustic Flow Monitor, U.S. Geol. Surv. Open File Rep., 95-114.

Havens, S., H.-P. Marshall, J. B. Johnson, and B. Nicholson (2014), Calculating the velocity of a fast moving snow avalanche using an infrasound array, Geophys. Res. Lett., 41, 6191-6198, doi:10.1002/2014GL061254.

Johnson, J. B., and M. Ripepe (2011), Volcano infrasound: A review, J. Volcanol. Geotherm. Res., 206, 61-69, doi:10.1016/j.jvolgeores.2011.06.006.

Johnson, J. B., J. Anderson, O. Marcillo, and S. Arrowsmith (2012), Probing local wind and temperature structure using infrasound from Volcan Villarrica (Chile), J. Geophys. Res., 117, D17107, doi:10.1029/2012JD017694.

Kogelnig, A., J. Hübl, E. Suriñach, I. Vilajosana, and B. W. McArdell (2014), Infrasound produced by debris flow: Propagation and frequency content evolution, Nat. Hazards, 70, 1713-1733, doi:10.1007/s11069-011-9741-8.

Lavigne, F., J.-C. Thouret, B. Voight, K. D. Young, R. HaHusen, J. Marso, H. Suwa, A. Sumaryono, D. S. Sayudi, and M. Dejean (2000), Instrumental lahar monitoring at Merapi Volcano, Central Java, Indonesia, J. Volcanol. Geotherm. Res., 100, 457-478, doi:10.1016/S0377-0273(00)00151-7. 
Lowe, D. R., S. N. Williams, H. Leigh, C. B. Connort, J. B. Gemmell, and R. E. Stoiber (1986), Lahars initiated by the 13 November 1985 eruption of Nevado del Ruiz Colombia, Nature, 324, 51-53, doi:10.1038/324051a0.

Lube, G., S. J. Cronin, V. Manville, J. N. Procter, S. E. Cole, and A. Freundt (2012), Energy growth of laharic mass flows, Geology, 40(5), 475-478, doi:10.1130/G32818.1.

Marcillo, O., J. B. Johnson, and D. Hart (2012), Implementation, characterization, and evaluation of an inexpensive low-power low-noise infrasound sensor based on a micro-machined differential pressure transducer and a mechanical filter, J. Atmos. Oceanic Technol., 29, 1275-1284, doi:10.1175/JTECH-D-11-00101.1.

Munoz-Salinas, E., V. C. Manea, D. Palacios, and M. Castillo-Rodriguez (2007), Estimation of lahar flow velocity on Popocatepetl volcano (Mexico), Geomorphology, 92, 91-99, doi:10.1016/j.geomorph.2007.02.011.

Neidell, N., and M. T. Taner (1971), Semblance and other coherence measures for multichannel data, Geophysics, 36(3), 482-497, doi:10.1190/1.1440186.

Palma, J. L., E. S. Calder, D. Basualto, S. Blake, and D. A. Rothery (2008), Correlations between $\mathrm{SO}_{2}$ flux, seismicity, and outgassing activity at the open vent of Villarrica volcano, Chile, J. Geophys. Res., 113, B10201, doi:10.1029/2008JB005577.

Pierson, T. C. (1985), Initiation and flow behavior of the 1980 Pine Creek and Muddy River lahars, Mount St. Helens, Washington, Geol. Soc Am. Bull., 96(8), 1056-1069, doi:10.1130/0016-7606.

Richardson, J. P., G. P. Waite, and J. L. Palma (2014), Varying seismic-acoustic properties of the fluctuating lava lake at Villarrica volcano, Chile, J. Geophys. Res. Solid Earth, 119, 5560-5573, doi:10.1002/2014JB011002.

Ripepe, M., S. De Angelis, G. Lacanna, P. Poggi, C. Williams, E. Marchetti, D. D. Donne, and G. Ulivieri (2009), Tracking pyroclastic flows at Soufriere Hills Volcano, Eos Trans. AGU, 90, 229-230, doi:10.1029/2009EO270001.

Siebert, L., and T. Simkin (2002), Volcanoes of the world: An illustrated catalog of Holocene volcanoes and their eruptions, Global Volcanism Program Digital Information Ser., GVP-3, edited, Smithsonian Institution. [Available at www.volcano.si.edu/world/.]

Vallance, J. W. (2000), Lahars, in Encyclopedia of Volcanoes, pp. 601-616, Academic Press, San Diego, Calif.

Van Daele, M., et al. (2014), The $600 \mathrm{yr}$ eruptive history of Villarrica Volcano (Chile) revealed by annually laminated lake sediments, Geol. Soc Am. Bull., 126(3/4), 481-498, doi:10.1130/B30798.1.

Yamasato, H. (1997), Quantitative analysis of pyroclastic flows using infrasonic and seismic data at Unzen Volcano, Japan, J. Phys. Earth, 45, 397-416, doi:10.4294/jpe1952.45.397. 